\title{
Efficient method of eliminating accidental damage of sewer tunnel
}

\author{
Dmitriy Goncharenko ${ }^{1}$, Olga Starkova $^{1}$, Alevtyna Aleinikova ${ }^{1, *}$, Yulyia Kolomiiets $^{1}$, and \\ Oksana Greenchuk ${ }^{1}$ \\ ${ }^{1}$ Kharkiv National University of Civil Engineering and Architecture, Sumska st. 40, 61002 \\ Kharkiv, Ukraine
}

\begin{abstract}
The article is devoted to the development of technological and organizational solutions for elimination of local emergency damage to sewage tunnel collectors. In the article, conditions of operation and constructions of the sewage tunnel collector destroyed by corrosion are investigated on Grekovska street in Kharkiv, Ukraine; the methods of production of repair and restoration works are analyzed in this article; technological and organizational solutions have been developed for the liquidation of emergency damage to sewage tunnel collectors, taking into account technical, organizational and economic indicators. Thus, when comparing recovery options by different methods, it is noted that the proposed technology is more economically feasible in view of the relatively low cost of the material for this solutions. At the same time, the duration of the work by the proposed method of extrusion by introducing a secondary lining with anticorrosive properties will be reduced by $30 \%$.
\end{abstract}

\section{Introduction}

The distribution system of sewerage utility systems is a sophisticated complex of facilities for sustainable sewage disposal. Its key elements include drainage pipelines and sewage tunnel collectors of various diameters characterizing the degree of development and redevelopment of a city. Under current conditions Ukrainian operating enterprises carry out their activities on the brink of their technological and organizational capabilities, as evidenced by high depreciation of fixed assets and emergency condition of many networks due to insufficient financing of the industry $[1,2]$. As of 2015, the total length of drainage networks in Ukraine was 37.404 thousand $\mathrm{km}$, including drainage networks in an emergency condition: 12.749 thousand $\mathrm{km}$ or $34 \%$ [3]. Compared with 2014, the total length of emergency drainage networks increased by $459 \mathrm{~km}$ or $3.6 \%$ for the whole country. Share of emergency drainage networks in Kharkiv in their whole length is $42 \%$. The trend of recent years indicates that the length of emergency networks increases annually by $0.67 \%$ [3].

Studies of many domestic and foreign scientists are devoted to operation, repair and reconstruction of sewage tunnel collectors [4-10]. D. Stein [11], M. Mahmoodian [12], N.

\footnotetext{
* Corresponding author: alevtynaal222@gmail.com
} 
Rohem [13], W. Wang [14], M. Anbari [15] and other researchers of non-CIS countries studied various issues of construction of deep-laid sewage tunnel collectors, examination of their state, methods of repair and reconstruction. Meanwhile, the analysis of the publications of the above authors provides a basis to conclude that issues of research and development of economically viable private methods of reconstruction of sewage tunnel collectors is topical. This especially applies to tunnel collectors whose structures are subject to corrosion to a significant extent, which can lead to irreversible environmental consequences.

The improvement of operation of sewage pipelines and sewage tunnel collectors, the increase of their reliability is an important problem, which is still not fully resolved, so there is an urgent need to develop organizational and technological solutions for the sustainable operation of underground utility lines of the sewage system.

The purpose of this paper is to develop technological and organizational solutions for the elimination of accidental damages caused to sewage tunnel collectors.

The following tasks are formulated in the paper for achieving this purpose:

- to study conditions of operation and structures of the sewage tunnel collector on Grekovskaya street in Kharkiv destroyed by corrosion,

- to analyze methods of performance of repairing and reconstruction works,

- to develop technological and organizational solutions for the elimination of accidental damages caused to sewage tunnel collectors with the consideration of performance indicators.

\section{Materials and methods}

Discharges aggressive to concrete may likely appear in the urban sewerage system with its mixture of various discharges (industrial and household wastewater and storm water). At the same time, as numerous collapses of sewage tunnel collectors show, concrete and reinforced concrete structures cannot remain operable within their guaranteed service life (20-30 years) and often get out of order before its expiration [1]. With this regard, the main cause of collapses is the exposure of their arch surfaces to biogenic corrosion. When considering the possibility of reconstruction of structures of sewage tunnel collectors, special attention must be paid to corrosion of concrete and reinforced concrete structures: their widespread use resulted in a current emergency condition of almost tunnel collectors constructed and commissioned since the early 1950s.

For example, in January 2018 the asphalt-concrete surface on Grekovskaya street (Kharkiv, Ukraine) was initially damaged and sagged. As a result of the accident, a cavity with an approximate depth of $10 \mathrm{~m}$ and a diameter of $20 \mathrm{~m}$ appeared in a short time in the concrete sewage tunnel collector constructed in 1972, and the adjacent building collapsed. The tunnel was arch-type, its diameter was $\mathrm{D}=2540 / 2850 \mathrm{~mm}$ (diameter of the clear opening was $\mathrm{D}=2140 / 2450 \mathrm{~mm}$ ), it was made of prefabricated reinforced concrete structures (M300 grade concrete) by shield tunneling with the use of the PShch-3,2 tunneling shield. It can be seen in the soil geological section that the tunnel was cut at a depth of $15 \mathrm{~m}$ in semi-solid clay and fine-grained watered sand at the groundwater level.

The accidental damage was caused to the deep-laid main collector tunnel in shafts 8 and 2 on the Grekovskaya street at the switching area of the main collector. The distance between the shaft No. 8 and the shaft No. 2 is $126 \mathrm{rm}$. The collapse area is in close proximity to the wastewater stilling chamber (shaft No. 8). The main cause of the local collapse is damage caused to the reinforced concrete arch of the tunnel collector by biogenic corrosion. Waste water in the stilling chamber falls from the mark 95.8 to the mark of the channel of the bypass sewage tunnel $83.9(\mathrm{H}=11.9 \mathrm{~m})$. As a result of the stratification of the flow, gaseous sulfur trioxide is actively released, and it is converted into 
high-concentration sulfuric acid during subsequent reactions. In the absence of anticorrosive protection, concrete lining of the tunnel collector, which bears load of the soil column, becomes damaged. The collapse of the supporting arch structure resulted in moving soil inside the tunnel collector with further fall and collapse of the adjacent building.

The procedure for the elimination of accidents in sewage networks is stipulated by the technical operation rules for water supply and wastewater disposal systems of residential areas of Ukraine, approved by the Order No. 30 of July 05, 1995. Organizational and technological measures for the elimination of local damage to an operating tunnel collector with open access to soil inside it include pre-construction and basic works. At the first stage, it is necessary to stop the soil washing and to ensure the drainage of wastewater by switching to a reserve collector or by installing a bypass line. But there was no technical capability to switch the tunnel collector on the Grekovskaya street to another line, and a bypass line was installed in the shaft, that allowed to ensure the functioning of the water distribution and disposal system (Fig. 1). Main organizational and technological operations of the preparatory stage include:

- fencing of the emergency work site,

- arrangement of wastewater drainage via three lines of the PE pipeline $(D=300 \mathrm{~mm})$ with pumping stations,

- conducting the geological engineering survey in the emergency area,

- backfilling of the collapse cavern with soil to prevent further collapsing,

- conducting geophysical studies on the basis of the actual state of the soil mass with the indication of sheeting limits, karst caverns, existing ground water tables for the subsequent development of a practicable design solution for the method of reconstruction.

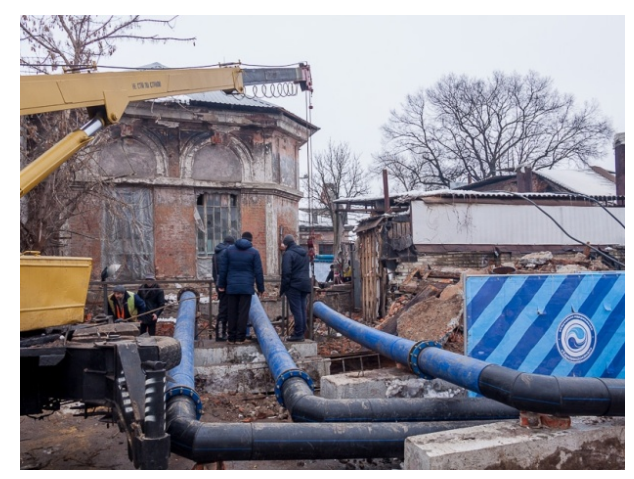

Fig. 1. Temporary disposal of wastewater.

The following was determined on the basis of the geophysical study report for the soil mass of the tunnel collector on Grekovskaya street from the shaft No. 8 to the shaft No. 2:

1. The absence of karst caverns in soil and the absence of loose soil over the arch part of the existing tunnel collector prove the integrity of the reinforced concrete lining of the sewage tunnel collector (its integrity was not established),

2. Small caverns and loose soil were found near the cavity over the existing tunnel line,

3. The survey was conducted in the subsoil waterlogging area. The ground water table is at the mark 98.5. The waterproof layer at the mark 94 consists of sandstones and marl. The aquifer is $4.5 \mathrm{~m}$ thick.

In the absence of a detailed study of the extent of the consequences of the accident and due to the unpredictability of conditions, it was resolved to fully fill the collapse cavern to enable subsequent development of technological solutions for the method of reconstruction 
of the tunnel collector on Grekovskaya street. To repair the damaged sewage tunnel collector, the following organizational and technological solutions may be used:

- full filling of the cavity, decommissioning of the damaged collector, construction of the new sewage tunnel collector (method 1);

- penetration into the cavity and reconstruction by inserting short polyethylene pipes (method 2);

- penetration into the cavity and reconstruction by the pipe-in-pipe method with the use of fiberglass pipes (method 3);

- penetration into the cavity by extrusion and reconstruction of the tunnel collector by introducing a secondary lining made of reinforced concrete rings with anti-corrosion coating (method 4).

The following technological scheme for repairing the sewage tunnel collector with penetration into the cavity by extrusion and further introducing a secondary lining made of reinforced concrete supporting rings with anticorrosive properties was developed. At the first stage, the tunnel shaft must be constructed on a curved section of the tunnel line to enable the performance of the works in both directions. Penetration into the cavity by extrusion must be made consistently from both sides by introducing reinforced concrete rings from the starting shaft No. 8 and the shaft No. 2. Reinforce concrete slabs in the stilling chamber No. 8 must be removed before such penetration to enable placing of working equipment and reinforced concrete rings inside the tunnel collector. Equipment for extrusion and reinforced concrete rings must also be installed in the reconstructed tunnel shaft. Then horizontal wells must be drilled through the soil in the cavity and steel rods with the detachable cutting edge must be pulled from both operating shafts. Pulling force applied to the cutting edge (ring-shaped) cuts the soil mass and introduces the rings in it. The supporting part of a reinforced concrete ring ensures the necessary rigidity and strength of the entire structure. Hydraulic jacks on the back side of the supporting ring embed the reinforced concrete rings with anti-corrosion coating in soil, and with this regard the precast lining is used as a jack pot for the jacks installed around the body. Then the jacks must be removed, and the area behind the supporting part must be reinforced with reinforced concrete components comprising the lining of the tunnel collector, if the cavity is being eliminated by extrusion. At the next stage, after the excavation of the next batch of soil, jacks push the cutting edge being supported by the components just installed.

The reconstruction is being performed step by step; each step depends on the maximum extension of rods of the hydraulic jacks. Soil is being excavated and removed manually with the use of hand-held power tools and small-size rock-removal wheeled machines.

After penetration into the cavity and installation of the secondary lining made of reinforced concrete rings, joints between reinforced concrete rings must be sealed with rapid setting expansive cement, and a cement and sand mortar must be injected in the interlining gap. The quality of the primary injection (i.e. filling the voids) must be checked by secondary control injection of the cement mortar.

When comparing the options of elimination of the accidental damage, it was taken into account that some operations to be performed in all four reconstruction options (methods 14) may be excluded, namely the preparation of the tunnel collector for reconstruction (in particular, switching waste water flows coming from the collector, preparation of starting and target shafts, etc. When reconstructing of the sewage tunnel collector with the use of trenchless reconstruction methods (methods $2,3,4$ ), it was taken into account that the space between pipes has to be filled with concrete of the same volume and the same composition in both options: with polyethylene and fiberglass pipes. In the developed technology of reconstruction of the sewage tunnel collector by extrusion by introducing a secondary lining made of reinforced concrete rings with anticorrosive properties, the volume of 
concrete used for filling the space between pipes was less than the volumes of concrete used for methods 2 and 3 .

The comparison of duration of reconstruction indicated for each option in the tables 1 and 2 gives us the possibility to conclude that the optimal duration of the work will be reached with the use of a method of penetration into the cavity by extrusion by introducing a secondary lining made of reinforced concrete rings with anticorrosive properties.

Table 1. Cost factors for materials used for elimination of the accidental damage caused to the sewage tunnel collector.

\begin{tabular}{|c|l|c|c|c|}
\hline $\begin{array}{c}\text { No. of the } \\
\text { reconstruction } \\
\text { method }\end{array}$ & \multicolumn{1}{|c|}{ Structures } & $\begin{array}{c}\text { Rated } \\
\text { diameter } \\
\text { DN }\end{array}$ & Unit & $\begin{array}{c}\text { Price per } \\
\text { unit*, UAH }\end{array}$ \\
\hline 1 & Polyethylene pipe Spiro & 1600 & $\mathrm{rm}$ & 35650.00 \\
\hline 2 & Polyethylene pipe Spiro & 1600 & $\mathrm{rm}$ & 29300.00 \\
\hline 3 & Fiberglass pipe & 1600 & $\mathrm{rm}$ & 28400.00 \\
\hline 4 & $\begin{array}{l}\text { Reinforced concrete ring with } \\
\text { anti-corrosion coating }\end{array}$ & 1600 & $\mathrm{rm}$ & 9800.00 \\
\hline
\end{tabular}

*prices are valid as of February 2018.

Table 2. Duration of elimination of the accidental damage caused to the tunnel collector on Grekovskaya street with the use of the mentioned methods (length of the site: $100 \mathrm{rm}$, diameter of the cavity: $20 \mathrm{rm})$.

\begin{tabular}{|c|l|c|}
\hline No. & \multicolumn{1}{|c|}{ Reconstruction method } & $\begin{array}{c}\text { Duration in days, three- } \\
\text { shift work }\end{array}$ \\
\hline 1 & $\begin{array}{l}\text { Full filling of the cavity, decommissioning of the } \\
\text { damaged collector, construction of a new sewage tunnel } \\
\text { collector (method 1) }\end{array}$ & 15 \\
\hline 2 & $\begin{array}{l}\text { Reconstruction by inserting short polyethylene pipes } \\
\text { (method 2) }\end{array}$ & 12 \\
\hline 3 & $\begin{array}{l}\text { Reconstruction by the pipe-in-pipe method with the use } \\
\text { of fiberglass pipes (method 3) }\end{array}$ & 9 \\
\hline 4 & $\begin{array}{l}\text { Reconstruction by extrusion by introducing a secondary } \\
\text { lining (method 4) }\end{array}$ & \multicolumn{2}{|l}{} \\
\hline
\end{tabular}

\section{Conclusions}

The studies carried out gave the possibility to develop an economically and technologically effective technology of elimination of possible local collapses of sewage tunnel collectors. The method of extrusion for penetration into the cavity was proposed for reconstruction. When comparing different options of reconstruction (methods 1-4), it should be noted that the proposed technology is more economically feasible than the pipe-in-pipe method with the use of polyethylene or fiberglass pipes in view of high cost of the materials in the latter case. At the same time, the duration of the work by the proposed method of extrusion by introducing a secondary lining made of reinforced concrete rings with anticorrosive properties will be reduced by $30 \%$ in comparison with the methods $1-3$. 


\section{References}

1. D. Bondarenko, V. Bulhakov, A. Garmash, D. Goncharenko, S. Pilihram, Kanalizatsiini tuneli Kharkova: QUO VADIS, 232 (2018)

2. A. Aleynikova, V. Volkov, D. Goncharenko, G. Zubko, O. Starkova, Methodological Foundations of Extension of the Operation Life of Underground Utility Networks, 320 (2017)

3. O. Kravchenko, O. Yamko, Book of Reports of the International Congress and Engineering Exhibition "ETEWS-2017", 7, 86 (2015)

4. I.A. Abramovich, Globus, Wastewater Networks and Facilities. Calculations, Designing, Operation, 288 (2005)

5. A. Garmash, D. Bondarenko, G. Zubko, D. Goncharenko, World Journal of Engineering, 13, 72 (2016)

6. V. Vasilyev, Yu. Klementyev, Yu. Stolbikhin, Water Supply and Sanitary Engineering, 1, 58 (2016)

7. V. Orlov, V. Kharkin. ROST, 3, 20 (2001)

8. A. Kovalenko, Development of Technological Solutions Used to Improve the Efficiency of Elimination of Accidents with Sewage Tunnel Collectors, 138 (2002)

9. D. Goncharenko, A. Aleinikova, V. Volkov, S. Zabelin, Eastern-European Journal of Enterprise Technologies, 6, 21 (2016)

10. A. Aleinikova, Actual Problems of Economics, 8, 224 (2016)

11. D. Stein. Ernst und Sohn, Instandhaltung von Kanalisationen, 941 (1999)

12. M. Mahmoodian, A. Alani Mahmoodian, Journal of Materials in Civil Engineering, 29, 1001 (2017)

13. N. Rohem et al., Composite Structures, 152, 737 (2016)

14. W. Wang et al., Engineering Failure Analysis, 81, 254 (2017)

15. M. Anbari, T. Massoud, R. Abbas, Journal of environmental management, 190, 91 (2017) 